\title{
Migración interna de la población con derecho a votar entre estratos de bienestar social, 2010-2015
}

\section{Internal migration of the eligible voters by social strata of welfare, 2010-2015}

\author{
Virgilio Partida-Bush
}

Facultad Latinoamericana de Ciencias Sociales

FLACSO - Sede México

\section{Resumen}

Con base en la Encuesta Intercensal 2015, de donde se extraen los migrantes, su educación y salarios, y las estimaciones municipales de pobreza del CONEVAL, se construyen cinco estratos de bienestar, para identificar migraciones de población con derecho a votar entre esos estratos durante el periodo 2010-2015. Al conjunto de municipios en que circunscribe una zona metropolitana o conurbación se le considera como una sola unidad geográfica para fines de la migración. Aparte se inspecciona la movilidad intraurbana. Se analizan los flujos totales y para tres etapas del ciclo de vida, asociadas a amplios rangos de edad. Se inspeccionan los diferenciales por sexo, y se exploran las diferencias en cuanto a educación y salarios de los migrantes y no migrantes.

Palabras clave: Migración interna, votantes, bienestar.

\section{Abstract}

From the Intercensal Survey 2015, where take the migrants, their education and wages, and from the CONEVAL the municipal estimates of poverty. We make five strata of welfare, to identify migration between these strata, during the period 2010-2015, of population eligible to vote. The set of municipalities that are part of the same metropolitan area or conurbation is considered as a single geographical unit for migration purposes. Also is inspected the intra-urban mobility. We analyze flows for total population and three stages of the life cycle, equaled to broad age-groups. We inspect differentials by sex, and we explore the differences in education and wages of migrants and non-migrants.

Keywords: Internal migration, voters, welfare. 


\section{INTRODUCCIÓN}

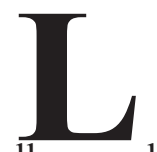

a pretensión por explicar de los desplazamientos territoriales, esto es, responder a la pegunta ¿por qué la gente migra? o, si se quiere, ¿cuáles son las condiciones o los determinantes que llevan a los individuos a tomar la decisión de migrar?, ha consistido - en buena medida- de la extensión de postulados básicos, extraídos de las teorías desarrolladas en las ciencias sociales, a uno de los procesos sociales específicos como es la migración. Tanto la sociología como la economía, la antropología y la política han hecho importantes aportes para entender mejor la ocurrencia de las migraciones; no obstante, si bien profusa la investigación que analiza el impacto de la migración internacional en los comicios electorales de un país; es escasa la indagación sobre la influencia de la migración interna en las votaciones.

Ha sido ampliamente documentado, que — en su menaje — los migrantes incluyen sus usos y costumbres de sus lugares de origen, y que - conforme pasa el tiempo - los modifican y adaptan a la idiosincrasia del lugar de destino; no obstante, es poco lo que se sabe, si es que se conoce algo, de si en el equipaje también agregan sus preferencias electorales (partidos políticos) del lugar del origen y si los cambian al paso de los años en su nueva residencia.

La escasa evidencia se debe al principio secreto del voto; y, si bien, en las llamadas "encuestas de salida" se pueden conocer las preferencias electorales, e incluso identificar la migración (lugar de nacimiento o residencia previa) del votante, es difícil (seguramente impreciso) indagar por las predilecciones eleccionarias previas en su lugar de origen.

El objetivo de este trabajo no es, de ninguna manera, inspeccionar la prevalencia o cambio de las preferencias electorales de los migrantes o de los no migrantes; tan solo identificar las direcciones de los flujos migratorios dentro de las fronteras de los Estados Unidos Mexicanos, de la población con edad y derecho a votar.

Existen diversas formas de identificar la orientación de los flujos migratorios, las más comunes son dos:

1. Dividir el territorio nacional en regiones, esto es, territorios contiguos, por lo general mediante el agrupamiento de entidades federativas colindantes. 
2. Dividir en estratos, donde se reúnen las unidades geográficas de acuerdo a cierta característica como, por ejemplo, el tamaño de la localidad, donde claramente solo las de menor tamaño - digamos las ruralesforman un continuo territorial.

En este trabajo usamos el segundo criterio, estratificando los municipios de acuerdo con el porcentaje de población en situación de pobreza, usando las valoraciones del Consejo Nacional de Evaluación de la Política de Desarrollo Social (CONEVAL) para nuestros fines.

Después de una breve discusión del concepto de migración y de la formación de los estratos de municipios, inspeccionamos los desplazamientos territoriales de la población en edad de votar, sus niveles educativos y sus salarios.

\section{EL CONCEPTO DE MIGRACIÓN, LA FORMACIÓN DE ESTRATOS TERRITO- RIALES Y LA POBLACIÓN CON DERECHO A VOTAR}

La migración alude a un desplazamiento territorial; sin embargo, no todos los traslados son migraciones, es necesario acotar el concepto para precisar el tipo de movimientos al que nos estamos refiriendo cuando hablamos de migraciones o de migrantes.

El cambio de residencia - definitivo o temporal - es la primera característica aceptada de manera común al definir la migración; no obstante, es conveniente que "la reanudación de la vida (sea) en un lugar nuevo y distinto" (Elizaga y Macisco, 1975: 8). Oberai (1989: 14-18) sugiere tomar en cuenta cuatro aspectos, que incorporan ambas ideas: espacio, residencia, tiempo y cambio de actividad. Los tres primeros criterios quedan de alguna manera comprendidos en el cambio de residencia habitual (temporal o definitiva) de un territorio a otro; no obstante, en el ámbito espacial, el autor propone que se quede fuera del área de influencia de un pueblo o de una ciudad para que el traslado sea efectivamente una migración, es decir, "en un lugar nuevo y distinto".

La restricción temporal nos permite identificar mejor el cambio en la dirección de los traslados: la modificación del modelo económico, por lo general, modifica la orientación de las mudanzas y las características de los migrantes (Partida, 2006). La inclusión del cambio de actividad puede cuestionarse, ya que es más bien inherente a la migración, a las condiciones sociales, económicas, políticas y culturales que determinan o propician los desplazamientos territoriales, y no tanto el traslado mismo. 
En suma, para los fines de este trabajo, se considera como migración el cambio de residencia habitual de manera individual o colectiva que implica quedar fuera del área de influencia de la unidad geográfica de donde se sale.

Nuestra fuente de datos es la Encuesta Intercensal de 2015 de México. La dimensión temporal se refiere al quinquenio previo al recuento poblacional, es decir, el municipio o país de residencia cinco años antes. El municipio de residencia al momento de la enumeración de habitantes es la unidad geográfica de destino y donde vivían en 2010 la de origen; no obstante, consideramos como no migrantes a quienes se desplazan dentro de una zona metropolitana o conurbación que comprenda dos o más municipios. ${ }^{1}$ Con el fin de identificar los cambios de residencia dentro de esas metrópolis o conurbaciones, en un análisis aparte inspeccionamos esos "traslados intra urbanos" ya que no son migraciones, en el sentido estricto, porque no quedan fuera del área de influencia de la ciudad, o bien, no cambian a "un lugar nuevo y distinto".

¿Por qué elegimos estratos en vez de regiones? Nuestra hipótesis es que la situación de bienestar, más que la residencia misma, puede ser más concluyente del voto por determinada corriente política.

De manera más específica, e indudablemente discutible, es que dado la fuerte correlación entre bienestar y educación, si bien no del todo, es más probable que los menos educados voten por quienes les prometan las mejores condiciones de bienestar a futuro. Si este razonamiento fuera cierto, se pudiera suponer, como una burda aproximación, que entre los migrantes prevaleciera la distribución del voto de sus lugares de origen, y se tuviera una idea gruesa del impacto de la migración en las elecciones en los lugares de destino.

\section{Metodología}

En la construcción de los estratos, utilizamos el criterio de pobreza multidimensional reportado por el CONEVAL (2014), que incluye la pobreza monetaria, es decir, los recursos financieros que son insuficientes para cubrir las necesidades básicas de la población (alimentarias y no alimentarias)², y

\footnotetext{
${ }^{1}$ De SAGARPA, CONAPO e INEGI (2018) tomamos la delimitación territorial de las 58 zonas metropolitanas de 2015 y dejamos de lado 16 que se componen de un solo municipio, porque la Encuesta Intercensal de 2015 no capta movilidad territorial dentro del municipio. Asimismo, agregamos 25 conurbaciones identificadas por SEDESOL y CONAPO (2012) para 2010 que se circunscribían a dos municipios.

${ }^{2}$ Las no alimentarias incluyen el gasto en transporte público; limpieza, cuidados, servicios de conservación y mantenimiento de la vivienda; cuidados personales; educación, cultura y recreación; comunicaciones y servicios para vehículos; prendas de vestir, calzado y accesorios; crista-
} 
derechos humanos básicos. ${ }^{3}$ Para simplificar la exposición, consideramos en situación de bienestar a quienes no padecen pobreza multidimensional.

Se clasifican a los municipios de acuerdo al complemento a cien del porcentaje de pobreza multidimensional, bajo la premisa que es más fácil pensar de manera positiva (bienestar) que negativa (pobreza) al inspeccionar las corrientes migratorias. ${ }^{4}$

Con base en el porcentaje del bienestar, se formaron cinco estratos mediante la técnica de conglomerados de $k$ medias, con la distancia euclidiana como medida de agrupamiento (STATA, 2003). En la Tabla 1 se reproduce la clasificación de los municipios en las cinco categorías y los puntos de corte de los estratos.

Se aprecia una distribución más equitativa de la población en los cinco estratos que de los municipios, lo cual se debe a que, por lo general, el bienestar es más frecuente en las áreas urbanas, con alta concentración de personas en los municipios y alcaldías, que en las rurales, con baja densidad poblacional. Si bien más de la mitad de las personas residían en municipios de muy alto y alto bienestar (56.3 por ciento), no se debe perder de vista que apenas 32 por ciento de los habitantes de ambos estratos cubrían sus necesidades y derechos humanos básicos. ${ }^{5}$

Hemos definido el concepto de migración y clasificado a los municipios según su proporción de residentes con bienestar; falta identificar a la población con derecho a votar. De acuerdo con los artículos 34 y 35 de la actual Constitución Política de los Estados Unidos Mexicanos (Reforma del 15 de septiembre de 2017), solo los ciudadanos mexicanos, es decir, las personas que hayan cumplido 18 años y tengan un modo honesto de vivir, pueden votar. Para ser ciudadano se requiere tener la nacionalidad mexicana, la cual se define en el artículo 30 de la misma Constitución y, en breve, se refiere, a los mexicanos por nacimiento, ${ }^{6}$ o por naturalización. ${ }^{7}$

\footnotetext{
lería, blancos y utensilios domésticos; cuidados de la salud; enseres domésticos; y artículos de esparcimiento.

${ }^{3}$ Rezago educativo, acceso a los servicios de salud, acceso a la seguridad social, calidad y espacios de la vivienda, acceso a los servicios básicos en la vivienda, acceso a la alimentación y grado de cohesión social.

${ }^{4}$ Debido a problemas en el levantamiento de la Encuesta Intercensal de 2015, no fue posible cubrir el mínimo de viviendas seleccionadas para garantizar la precisión deseada en el diseño muestral en once municipios del país: Buenaventura, Carichí, Santa Isabel, Temósachic y Urique en Chihuahua; Matías Romero Avendaño, San Francisco Chindúa, Santa María Chimalapa y Santa María Petapa en Oaxaca; San Nicolás de los Ranchos en Puebla; y General Plutarco Elías Calles en Sonora. A la población ponderada de la base de microdatos, se asoció el porcentaje de bienestar (o complemento a cien del de pobreza multidimensional) de 2010.

${ }^{5}$ El último porcentaje se extrae de la base de CONEVAL (2017), no de la Tabla 1.

${ }^{6}$ Nacidos en territorio mexicano o embarcaciones o aeronaves mexicanas, o en el extranjero de padres mexicanos.

${ }^{7}$ Extranjeros que obtienen carta de naturalización de la Secretaría de Relaciones Exteriores o que contraen nupcias con un ciudadano mexicano y cubren ciertos requisitos de legales.
} 


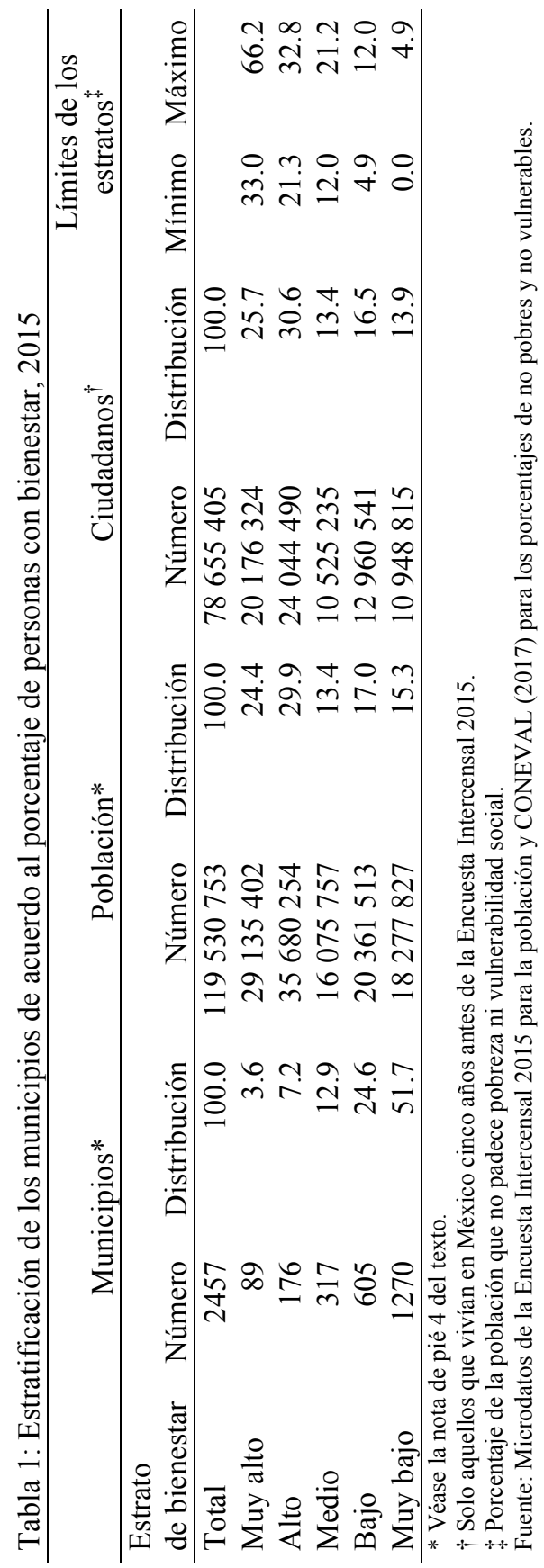


Conviene aclarar aquí una situación peculiar. Dado que el artículo 30 constitucional otorga la nacionalidad mexicana a nacidos en el extranjero, hijos de padre o madre mexicanos nacidos en territorio nacional o por naturalización, y tienen el derecho a votar aunque residan en otro país, aquí estamos interesados solo en quienes residen en territorio mexicano (contabilizados en la Encuesta Intercensal de 2015), ya que nuestro objetivo no es la votación per se, sino la migración de los ciudadanos mexicanos que viven en México.

En la Encuesta Intercensal de 2015 se incluyó una pregunta explícita sobre la nacionalidad para todos los residentes de la vivienda enumerada. Si bien una persona que carece de documentos para una estadía legal en territorio mexicano pudiera declararse mexicano, pensamos que esa imprecisión debe ser mínima.

En el tercer panel de la Tabla 1, se advierte que - en ambos años-, el reparto de los ciudadanos que vivían en México en 2015, está algo más concentrado que la población total en los dos estratos de bienestar más alto.

\section{FluJOS ENTRE Y DENTRO de LOS ESTRATOS}

Una primera visión de las migraciones de la población con derecho a votar, entre los cinco estratos de bienestar, la tenemos en la Tabla 2.

Si se atiende al origen (columna), se prefiere más el estrato de bienestar alto para establecer la nueva residencia que los cuatro restantes, excepto en la categoría más alta que optan más por mantenerse ahí

Cabe preguntarse si el patrón de preferencia del destino es independiente del origen. La prueba estadística $\chi^{2}$ de bondad del ajuste (Ostle, 1973: 155-156) indica que — en ambos sexos — se rechaza la hipótesis de independencia cual fuere el nivel de significancia $\alpha$, consistente por la inclinación por el estrato de alto bienestar.

¿Qué tan distintas son las distribuciones de los flujos migratorios entre los sexos? Con la prueba de Kolmogoroff y Smirnoff (Kolmogoroff, 1941) también se rechaza la hipótesis de independencia, para cualquier coeficiente de confianza, lo cual se debe a que — por lo general— la mayoría de los ciudadanos están consensualmente unidos y migran juntos. Asimismo, el alto coeficiente de correlación entre las veinticinco corrientes migratorias de ambos sexos (0.994) apuntala la semejanza en la orientación de los desplazamientos entre varones y féminas.

Tradicionalmente se acepta que las personas migran para mejorar sus condiciones de vida, siendo las económicas las que - al menos desde la perspectiva teórica- son de mayor importancia. 


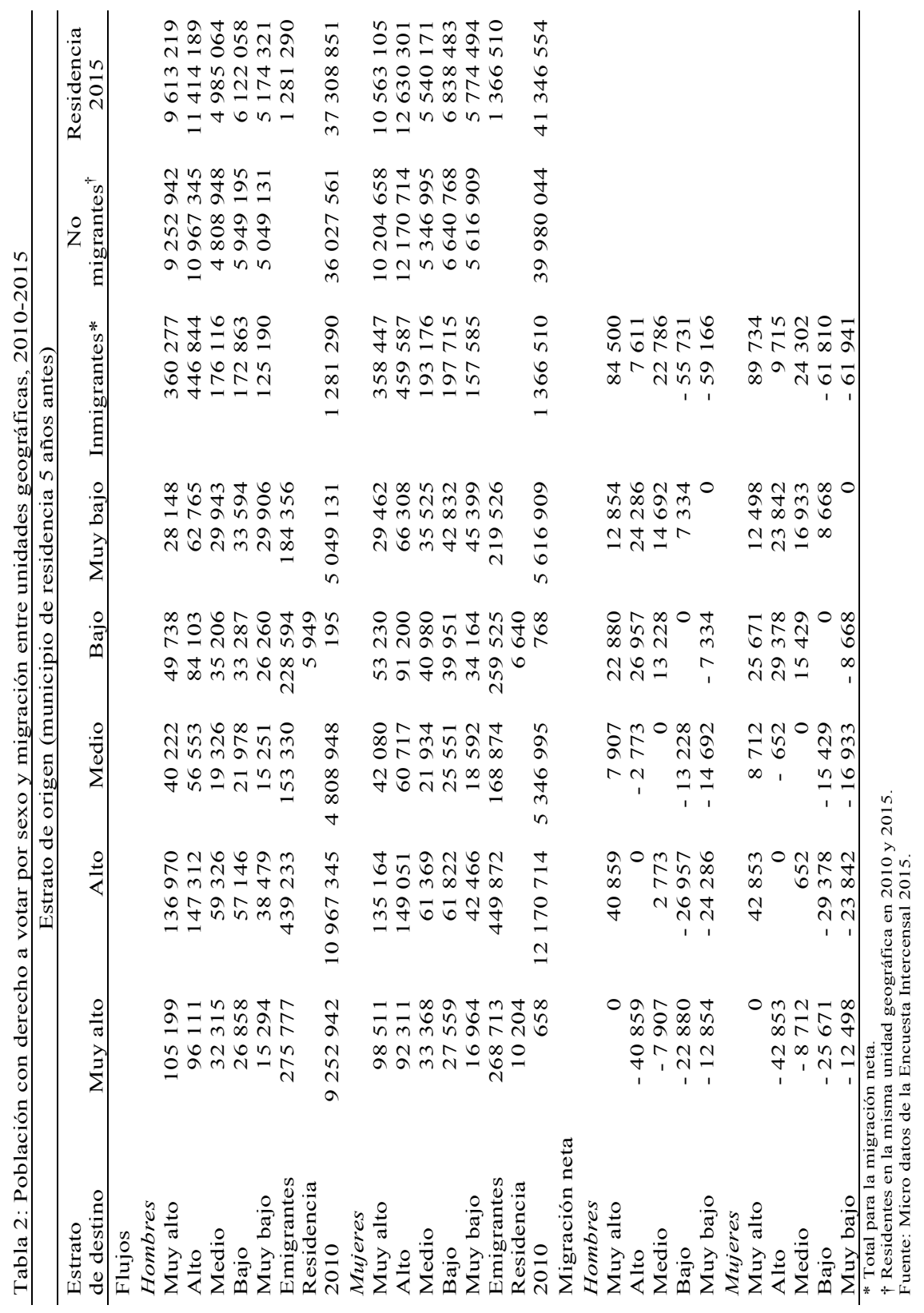


Esta premisa, sin embargo, no se cumple cabalmente en la Tabla 2; como apuntamos arriba, se opta más por el estrato de alto bienestar que por el de muy alto. Una posible explicación de este patrón, que contradice el postulado clásico de la migración, y sin que sea exhaustiva, es que además de la posibilidad de allegarse los recursos monetarios y la disponibilidad de servicios básicos (agua, drenaje, educación, salud, acceso a la cultura, entre otros), se toma en cuenta la inseguridad y la criminalidad en ciertas zonas del país; así, amén de la posible vulnerabilidad, se debe considerar la integridad física en el lugar de residencia.

Si bien estamos conscientes que una pregunta directa sobre una única causa de la migración ofrece solo una visión parcial de las razones para trasladarse, de acuerdo con la Encuesta Nacional de la Dinámica Demográfica de 2014, entre la batería de causas de la migración del quinquenio previo, 4.5 por ciento de los ciudadanos (nacidos en México de 18 años o más de edad) que se desplazaron eligieron la inseguridad o criminalidad, y para quienes se desplazaron en el año anterior 3.6 por ciento. ${ }^{8}$

En los dos sexos las llegadas más cuantiosas arriban al estrato de bienestar alto, pero también de ahí parten las salidas más numerosas, como se puede ver en la columna "inmigrantes" y el renglón "emigrantes", respectivamente, de la Tabla 2. No obstante, al descontar los emigrantes de los inmigrantes, es decir, la migración neta o saldo neto migratorio, no solo el estrato más alto exhibe la mayor ganancia neta por desplazamientos territoriales, sino que además la categoría alta es superada por el grupo de nivel medio, como se puede ver en los paneles inferiores de la Tabla $2 .{ }^{9}$

Es evidente que uno y solo un estrato puede tener ganancia o pérdida neta migratoria con relación a los demás estratos; aunque se puede dar el caso, como ocurre en los dos paneles inferiores de la Tabla 2, que uno tenga ganancia neta con los demás y el otro acuse pérdida neta con el resto.

Debido a la manera como el CONEVAL (2014) estima la proporción de pobres en cada municipio, y las restricciones propias de la información de la Encuesta Intercensal, es difícil saber si, efectivamente, los miembros de hogares específicos mejoraron su nivel de vida al migrar.

\footnotetext{
${ }^{8}$ De acuerdo con Martínez (2017), el coeficiente de variación de 14.2 por ciento del quinquenio previo indica que el porcentaje es de buena calidad; y para el año previo de 23.9 por ciento señala que la valoración es aceptable.

${ }_{9}^{9}$ La simetría de las migraciones netas con respecto a la diagonal principal, en los dos paneles inferiores del cuadro 2 , se debe a que inmigrantes y emigrantes se intercambian según el estrato de referencia. Por ejemplo, de acuerdo con el panel superior, 136,970 hombres llegan al estrato muy alto del alto (inmigrantes) y 96,111 lo hacen en dirección opuesta (emigrantes); desde la perspectiva del estrato alto, en relación con muy alto, los inmigrantes son 96,111 y los emigrantes 136,970 . Así, muy alto gana 40,859 ciudadanos con alto, misma cifra que este estrato pierde respecto de aquél.
} 
En la Tabla 3, reproducimos la movilidad intra urbana, es decir, las personas que se mudaron entre municipios de una misma zona metropolitana o conurbación. Debido al escaso tamaño de la muestra en la Encuesta Intercensal, tuvimos que agrupar los tres estratos de menor bienestar en uno solo, que denominamos "bajo". Esto se debe a que, si bien hay presencia de pobreza en las áreas urbanas, es mínima la proporción en comparación con el medio no urbano.

El patrón de movilidad es algo distinto al de la migración; ahora los desplazamientos más profusos se tienen dentro de cada uno de los estratos. E igual que en la migración, el estrato de alto bienestar es el que recibe, dentro de la misma zona metropolitana o conurbación, la mayor cantidad de nuevos residentes, pero también el que más expulsa.

En los paneles inferiores de la Tabla 3, se advierte que los estratos de mayor bienestar acusan pérdida neta de habitantes por movilidad intra urbana, con la ganancia neta resultante de bienestar bajo. Grosso modo, este patrón puede ser indicativo de las escasas posibilidades económicas de acceder al suelo urbano de mayor valor al mudar la residencia dentro de la misma urbe, y los hogares deben aceptar alguna pérdida de bienestar. Cabe acotar, que solo conocemos las condiciones de vida de las personas en 2015 pero no en 2010, con lo cual no sabemos si, efectivamente, hubo tal pérdida de bienestar.

Nuevamente, de acuerdo a la prueba estadística $\chi^{2}$ de bondad del ajuste, en ambos sexos se rechaza la hipótesis de independencia, cual fuere el nivel de significancia $\alpha$; y la prueba de Kolmogoroff y Smirnoff indica que se rechaza la independencia entre los sexos, como también se advierte en el coeficiente de correlación lineal entre hombres y mujeres (0.999).

\section{El CiClo de VIDA}

Las preferencias electorales pueden variar conforme el individuo envejece, esto puede deberse, entre muchos motivos, a que conforme pasa el tiempo, sus responsabilidades aumentan, como las laborales, pero - sobre todolas familiares y, por tanto, ego puede cambiar su percepción de la manera como las ofertas de los candidatos a puestos de representación popular se adaptan a sus necesidades.

La composición por edad de los migrantes se encuentra estrechamente vinculada al ciclo de vida de las personas y de los hogares. 
Migración interna de la población con derecho a votar entre estratos de bienestar social, 2010-2015 / V. PARTIDA BUSH

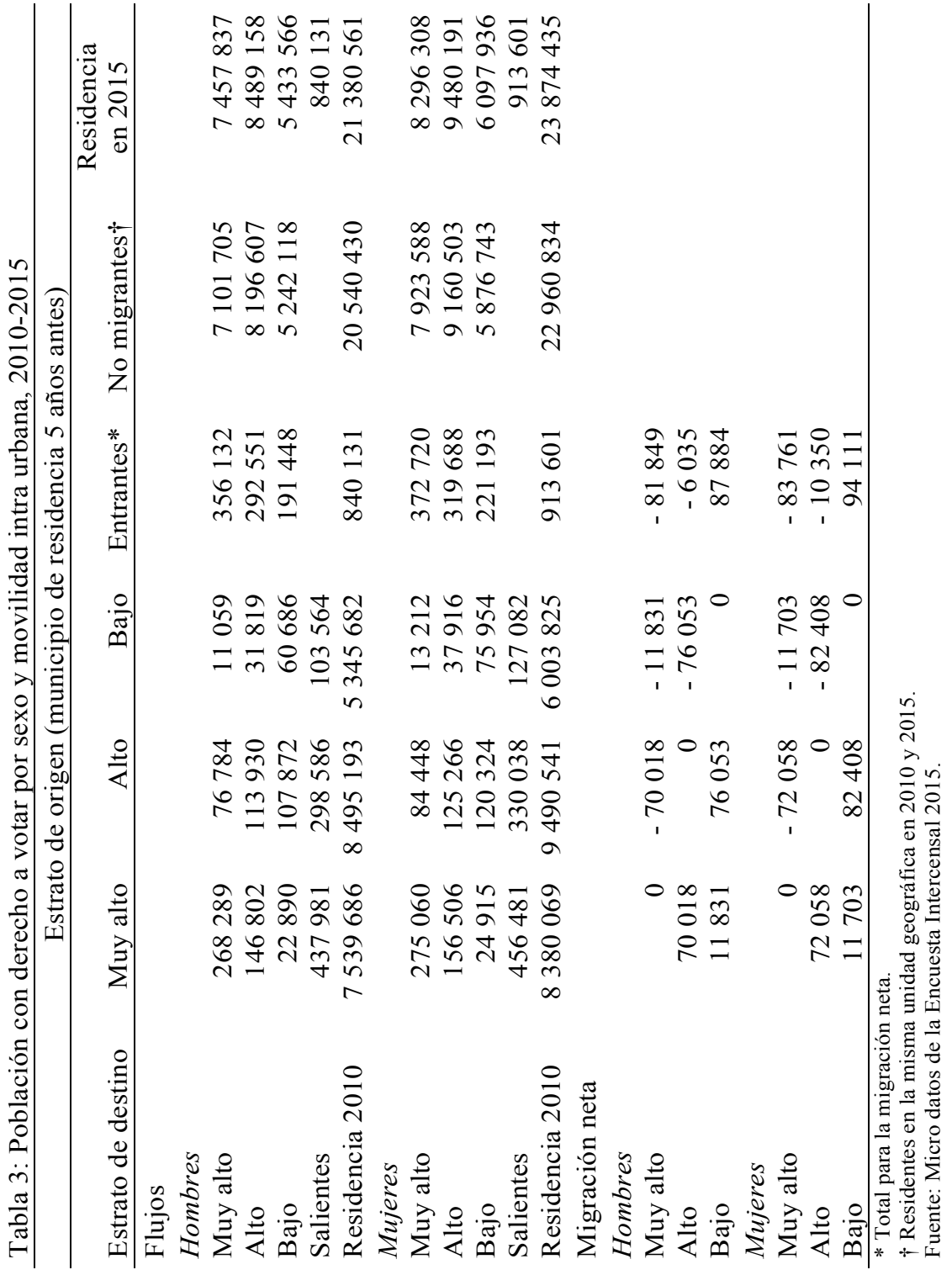


Generalmente, es en la juventud y las primeras edades adultas cuando los individuos migran porque dejan el hogar paterno, porque van a formar una nueva familia, porque al inicio de su vida laboral requieren desplazarse territorialmente para conseguir el empleo deseado o porque el cambio de residencia les permitirá garantizarse su sustento y el de sus familiares. Conforme avanza la edad, la situación familiar y laboral de los individuos es más estable y, por lo tanto, los desplazamientos espaciales son menos frecuentes. Y, en la fase de fisión, los progenitores son aún menos propensos a migrar, sea por limitaciones físicas propias de esa etapa de la vida, sea porque se han avecindado satisfactoriamente en su lugar de residencia.

De manera general, esos rasgos se advierten en la pirámide de edades para el total de migrantes entre unidades geográficas que se presentan en la Figura 1.

Para nuestros fines, dividimos el rango etario en tres intervalos: 18 a 29 años o adultez temprana, 30 a 59 años o adultez madura, y 60 años o más o adultez tardía. Así por ejemplo, sin ser exhaustivos, los más jóvenes esperarían la oferta educativa en nivel medio superior y superior y un empleo seguro y con prestaciones para su primera inserción laboral; los medianos, seguridad en el empleo y oferta educativa para su descendencia; y los mayores, amén de una pensión digna; y atención a la salud eficiente y completa. La mejor oferta y cumplimiento de los programas de los partidos políticos bien puede mover el fiel en la balanza electoral.

Los desplazamientos espaciales de las personas de esas tres etapas del ciclo de vida se reproducen en la Tabla 4a y en la Tabla 4b. En general, los rasgos anotados arriba para el total de la población (Tabla 2), se repiten en las tres etapas del ciclo de vida. Las contadas excepciones son, en el grupo 18 a 29 años, la corriente masculina más cuantiosa es hacia bienestar muy alto para las salidas de alto, y la femenina de bajo hacia medio que es menor que aquella dentro de bajo; de 30 a 59 años, en ambos sexos el flujo que parte de muy alto, donde el mayor es hacia alto, en los varones que dejan alto para ubicarse en bajo, que es mayor que para establecerse en medio, y en las féminas, ahora es mayor de muy bajo bienestar hacia bajo que dentro de muy bajo. Finalmente, entre los ciudadanos de mayor edad, en los hombres nuevamente la corriente que sale de muy alto es mayor es hacia alto, y los que permanecen en la categoría baja son más que los que de ahí se dirigen hacia media; en las mujeres, otra vez prefieren ascender a bajo que permanecer en muy bajo, y el flujo de alto hacia medio es mayor que de alto hacia bajo. 
Migración interna de la población con derecho a votar entre estratos de bienestar social, 2010-2015 / V. PARTIDA BUSH

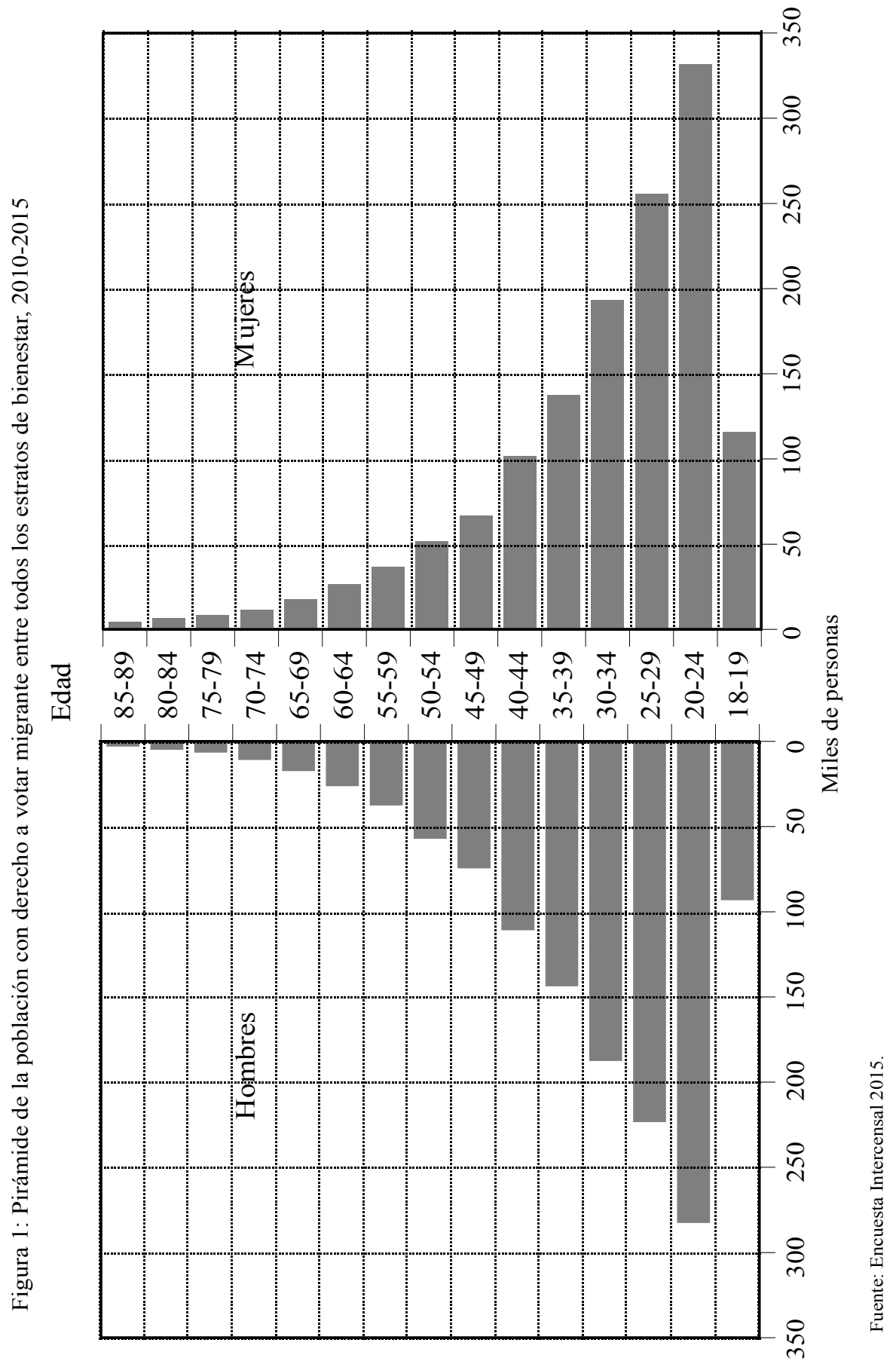




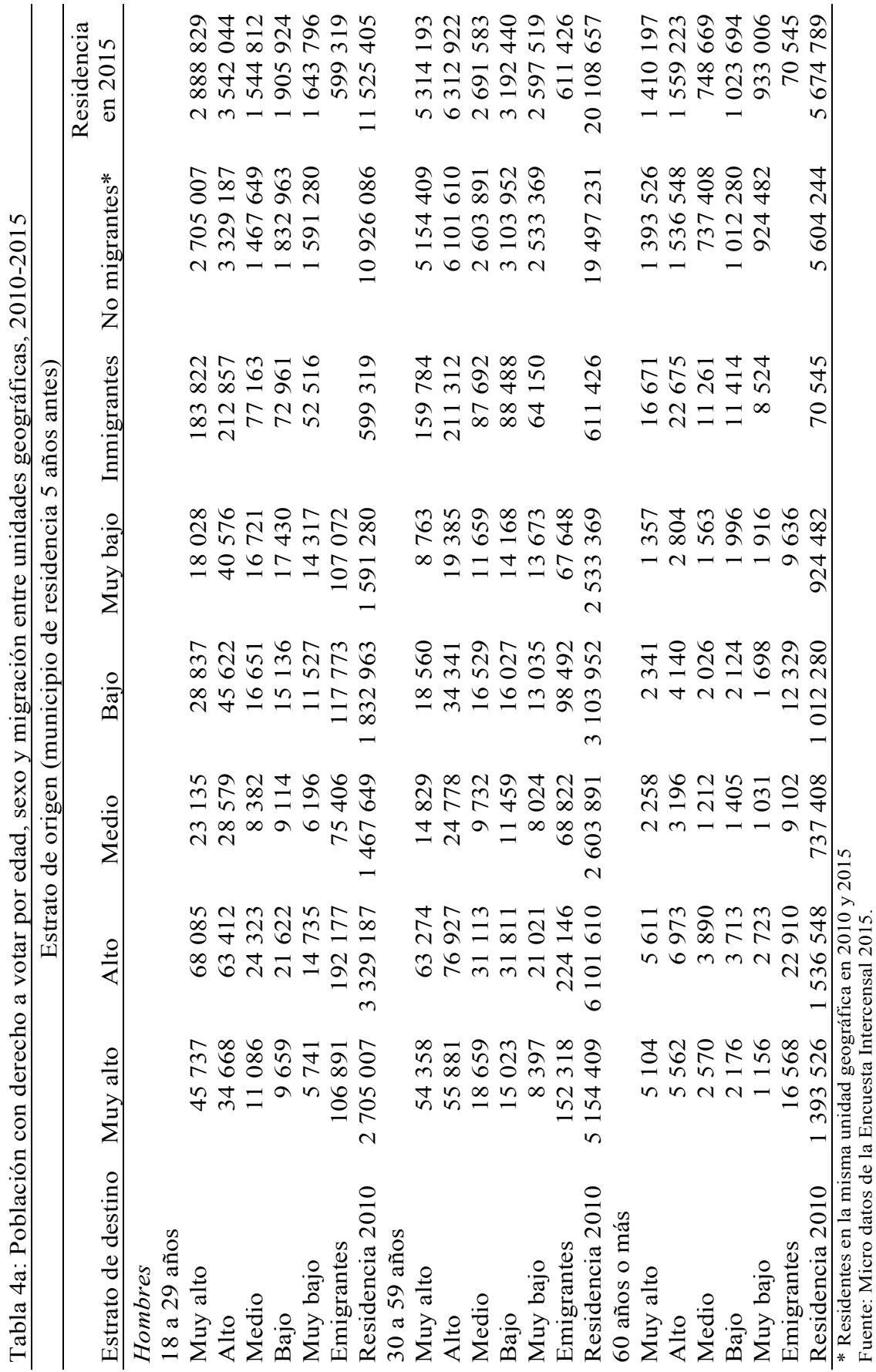




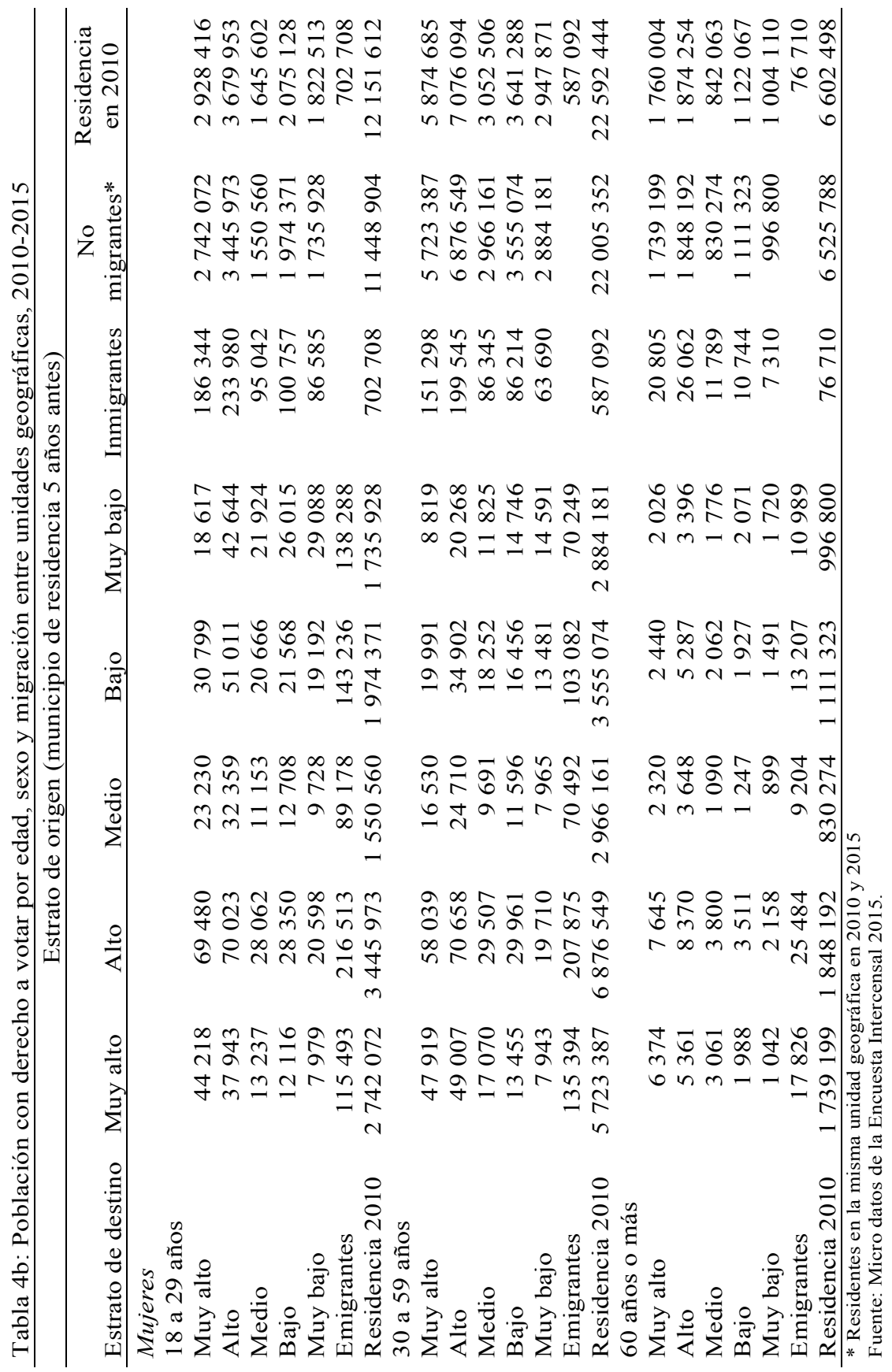


La prueba estadística $\chi^{2}$ de bondad del ajuste indica que, en ambos sexos, se rechaza la hipótesis de independencia, cual fuere el nivel de significancia $\alpha$; con la prueba de Kolmogoroff y Smirnoff se rechaza la independencia entre los sexos; y el coeficiente de correlación lineal entre sexos dentro de cada grupo de edad y entre intervalos etarios para sexo es de 0.879 o más.

En las migraciones netas de la Tabla 5 se advierten cambios más significativos respecto del total que en los flujos. Por ejemplo, solo en los más jóvenes en el estrato de más alto bienestar prevalece la ganancia neta con respecto a los otros cuatro estratos; mientras la pérdida generalizada de muy bajo se mantiene, excepto en los adultos maduros varones, donde hubo ganancia con la categoría alta.

$\mathrm{Al}$ inspeccionar el saldo neto migratorio total, en la última columna de la Tabla 5, en ambos sexos, se advierte en los más jóvenes un acrecentamiento poblacional mayor en alto que en bienestar medio, y decremento en alto entre los adultos maduros. Finalmente, se tiene la pérdida de los hombres de mayor edad en la categoría alta.

La Tabla 6 contiene la movilidad intraurbana de las tres etapas del ciclo de vida. Hemos juntado los dos sexos, debido a que la precisión de las estimaciones disminuye al separar en varones y féminas, dada la menor proporción de la muestra de la Encuesta Intercensal en zonas metropolitanas y conurbaciones.

A diferencia de la migración, casi no hay las disimilitudes en los desplazamientos dentro de las ciudades de los tres intervalos etarios con respecto al total; la única diferencia se tiene en los adultos mayores, donde los traslados de alta hacia baja son más voluminosos que dentro de alta, cuando se advierte la relación opuesta en los otros intervalos etarios.

Igual que en para el total de la población, en los tres grupos de edad se rechaza la hipótesis de independencia al aplicar las prueba estadística $\chi^{2}$ de bondad del ajuste en la orientación de los flujos, la de Kolmogoroff y Smirnoff entre intervalos etarios, para todo nivel de significancia $\alpha, y$ cualquiera sea el vínculo de sexos, total y grupos de edad, el coeficiente de correlación lineal es de 0.982 o más.

\section{LA INTENSIDAD DE LA MIGRACIÓN}

¿Quiénes son más propensos a migrar en las diversas edades? La respuesta la tenemos en la Figura 2. Como mencionamos arriba, el patrón se encuentra estrechamente vinculado al ciclo de vida de las personas y de los hogares. 
Tabla 5: Migración entre unidades de la población con derecho a votar por edad y sexo, 2010-2015

\begin{tabular}{|c|c|c|c|c|c|c|}
\hline \multirow{2}{*}{ Estrato de destino } & \multicolumn{6}{|c|}{ Estrato de origen (municipio de residencia 5 años antes) } \\
\hline & Muy alto & Alto & Medio & Bajo & Muy bajo & Total \\
\hline \multicolumn{7}{|l|}{ Hombres } \\
\hline \multicolumn{7}{|l|}{18 a 29 años } \\
\hline Muy alto & 0 & 33417 & 12049 & 19178 & 12287 & 76931 \\
\hline Alto & -33417 & 0 & 4256 & 24000 & 25841 & 20680 \\
\hline Medio & -12049 & -4256 & 0 & 7537 & 10525 & 1757 \\
\hline Bajo & -19178 & -24000 & -7537 & 0 & 5903 & -44812 \\
\hline Muy bajo & -12287 & -25841 & -10525 & -5903 & 0 & -54556 \\
\hline \multicolumn{7}{|l|}{30 a 59 años } \\
\hline Muy alto & 0 & 7393 & -3830 & 3537 & 366 & 7466 \\
\hline Alto & -7393 & 0 & -6335 & 2530 & -1636 & -12834 \\
\hline Medio & 3830 & 6335 & 0 & 5070 & 3635 & 18870 \\
\hline Bajo & -3537 & -2530 & -5070 & 0 & 1133 & -10004 \\
\hline Muy bajo & -366 & 1636 & -3635 & -1133 & 0 & -3498 \\
\hline \multicolumn{7}{|l|}{60 años o más } \\
\hline Muy alto & 0 & 49 & -312 & 165 & 201 & 103 \\
\hline Alto & -49 & 0 & -694 & 427 & 81 & -235 \\
\hline Medio & 312 & 694 & 0 & 621 & 532 & 2159 \\
\hline Bajo & -165 & -427 & -621 & 0 & 298 & -915 \\
\hline Muy bajo & -201 & -81 & -532 & -298 & 0 & -1112 \\
\hline \multicolumn{7}{|l|}{ Mujeres } \\
\hline \multicolumn{7}{|l|}{18 a 29 años } \\
\hline Muy alto & 0 & 31537 & 9993 & 18683 & 10638 & 70851 \\
\hline Alto & -31537 & 0 & 4297 & 22661 & 22046 & 17467 \\
\hline Medio & -9993 & -4297 & 0 & 7958 & 12196 & 5864 \\
\hline Bajo & -18683 & -22661 & - 7958 & 0 & 6823 & -42479 \\
\hline Muy bajo & -10638 & -22046 & -12196 & -6823 & 0 & -51703 \\
\hline \multicolumn{7}{|l|}{30 a 59 años } \\
\hline Muy alto & 0 & 9032 & -540 & 6536 & 876 & 15904 \\
\hline Alto & -9032 & 0 & -4797 & 4941 & 558 & -8330 \\
\hline Medio & 540 & 4797 & 0 & 6656 & 3860 & 15853 \\
\hline Bajo & -6536 & -4941 & -6656 & 0 & 1265 & -16868 \\
\hline Muy bajo & -876 & -558 & -3860 & -1265 & 0 & -6559 \\
\hline \multicolumn{7}{|l|}{60 años o más } \\
\hline Muy alto & 0 & 2284 & -741 & 452 & 984 & 2979 \\
\hline Alto & -2284 & 0 & -152 & 1776 & 1238 & 578 \\
\hline Medio & 741 & 152 & 0 & 815 & 877 & 2585 \\
\hline Bajo & -452 & -1776 & -815 & 0 & 580 & -2463 \\
\hline Muy bajo & -984 & -1238 & -877 & -580 & 0 & -3679 \\
\hline
\end{tabular}

Fuente: Tabla 4. 
Tabla 6: Población con derecho a votar por edad y movilidad intra urbana, 2005-2015

Estrato de origen (municipio de residencia 5 años antes)

\begin{tabular}{|c|c|c|c|c|c|c|}
\hline Estrato de destino & Muy alto & Alto & Bajo & Entrantes* & No migrantes $\dagger$ & $\begin{array}{c}\text { Residencia } \\
\text { en } 2015 \\
\end{array}$ \\
\hline \multicolumn{7}{|l|}{ Flujos } \\
\hline \multicolumn{7}{|l|}{18 a 29 años } \\
\hline Muy alto & 190147 & 56879 & 10629 & 257655 & 4084838 & 4342493 \\
\hline Alto & 101574 & 85519 & 28551 & 215644 & 5025361 & 5241005 \\
\hline Bajo & 15711 & 80692 & 57251 & 153654 & 3389401 & 3543055 \\
\hline Salientes & 307432 & 223090 & 96431 & & & 626953 \\
\hline Residencia 2005 & 4392270 & 5248451 & 3485832 & 626953 & 12499600 & 13126553 \\
\hline \multicolumn{7}{|l|}{30 a 59 años } \\
\hline Muy alto & 320972 & 94542 & 12129 & 427643 & 8358038 & 8785681 \\
\hline Alto & 181128 & 140926 & 38181 & 360235 & 9752214 & 10112449 \\
\hline Bajo & 28633 & 133624 & 72994 & 235251 & 6099758 & 6335009 \\
\hline Salientes & 530733 & 369092 & 123304 & & & 1023129 \\
\hline Residencia 2005 & 8888771 & 10121306 & 6223062 & 1023129 & 24210010 & 25233139 \\
\hline \multicolumn{7}{|l|}{60 años 0 más } \\
\hline Muy alto & 32230 & 9811 & 1513 & 43554 & 2582417 & 2625971 \\
\hline Alto & 20606 & 12751 & 3003 & 36360 & 2579535 & 2615895 \\
\hline Bajo & 3461 & 13880 & 6395 & 23736 & 1629702 & 1653438 \\
\hline Salientes & 56297 & 36442 & 10911 & & & 103650 \\
\hline Residencia 2005 & 2638714 & 2615977 & 1640613 & 103650 & 6791654 & 6895304 \\
\hline \multicolumn{7}{|l|}{ Migración neta } \\
\hline \multicolumn{7}{|l|}{18 a 29 años } \\
\hline Muy alto & 0 & - 44695 & -5082 & - 49777 & & \\
\hline Alto & 44695 & 0 & -52141 & - 7446 & & \\
\hline Bajo & 5082 & 52141 & 0 & 57223 & & \\
\hline \multicolumn{7}{|l|}{30 a 59 años } \\
\hline Muy alto & 0 & -86586 & -16504 & - 103090 & & \\
\hline Alto & 86586 & 0 & -95443 & -8857 & & \\
\hline Bajo & 16504 & 95443 & 0 & 111947 & & \\
\hline \multicolumn{7}{|l|}{60 años o más } \\
\hline Muy alto & 0 & -10795 & -1948 & -12743 & & \\
\hline Alto & 10795 & 0 & -10877 & -82 & & \\
\hline Bajo & 1948 & 10877 & 0 & 12825 & & \\
\hline
\end{tabular}


Migración interna de la población con derecho a votar entre estratos de bienestar social, 2010-2015 / V. PARTIDA BUSH

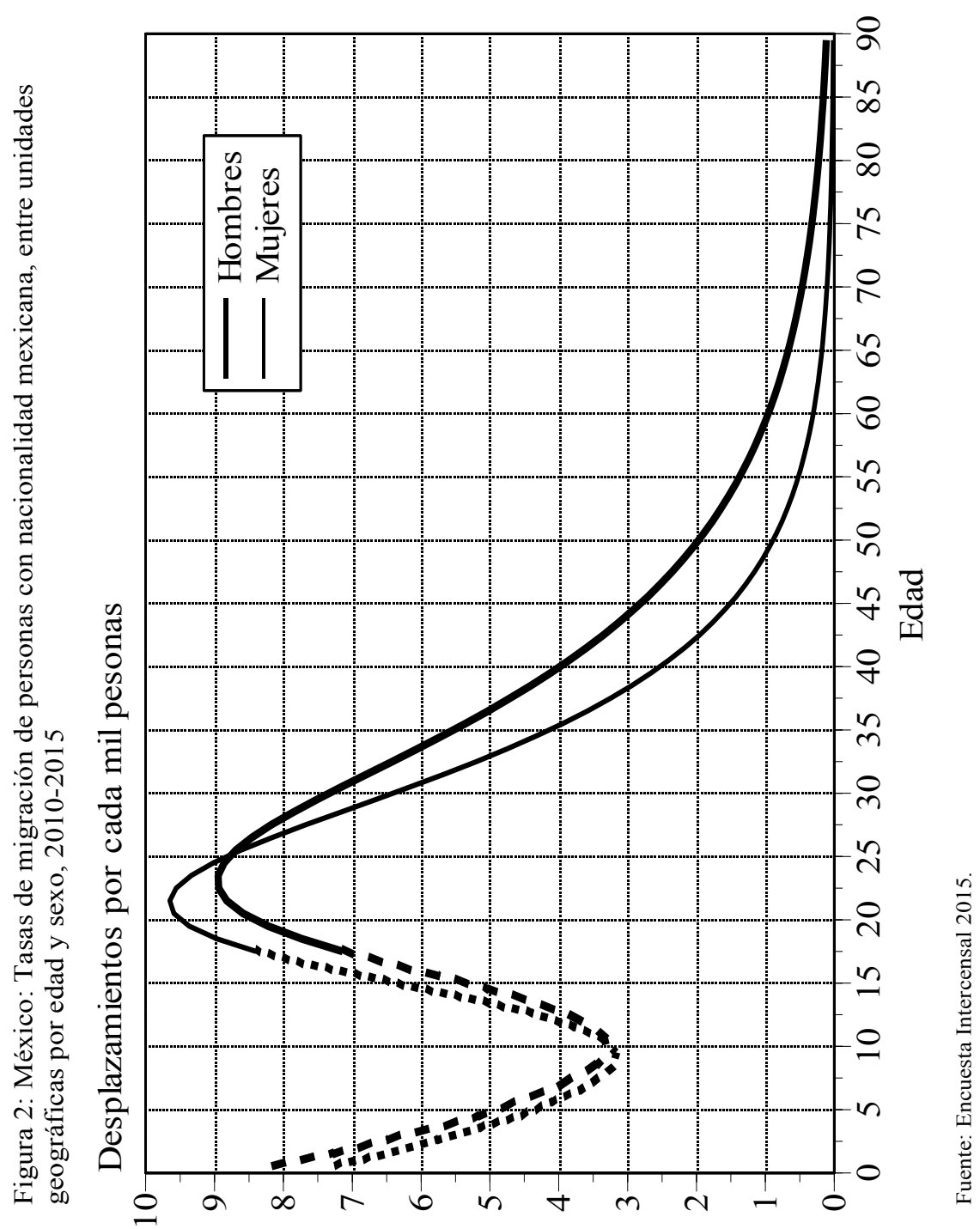


Generalmente, es en la juventud y las primeras edades adultas cuando los individuos migran porque dejan el hogar paterno, porque van a formar una nueva familia, porque al inicio de su vida laboral requieren desplazarse territorialmente para conseguir el empleo deseado o porque el cambio de residencia les permitirá garantizarse su sustento y el de sus familiares.

En las etapas iniciales de la constitución de la familia predominan los hijos pequeños, debido a que la duración de la unión aún es corta. Así, las altas tasas en la niñez indican que los infantes migran con sus padres dentro de un esquema - presumiblemente profuso - de migración familiar. Conforme avanza la edad, la situación familiar y laboral de los individuos es más estable y, por lo tanto, los desplazamientos espaciales son menos frecuentes. En la etapa de la expansión de la familia, la menor migración se advierte también en los hijos, quienes se encuentran todavía en edades escolares y permanecen en el hogar paterno.

En la fase de fisión-reemplazo, los progenitores son aún menos propensos a migrar, pero sus hijos comienzan a dejar el hogar, repitiéndose el ciclo de formación-expansión de nuevas familias.

Los movimientos territoriales en las etapas de disolución del hogar y de envejecimiento son de menor monto e intensidad que en las fases anteriores, y se asocian fuertemente al retiro de la actividad económica, sea para dejar la vida agitada de las ciudades buscando lugares más tranquilos para pasar los últimos años, sea para reunificarse con los hijos en búsqueda del sostén económico y afectivo del que carecen los adultos mayores.

De las funciones biométricas representadas por las curvas de la Figura 2 , solo estamos interesados en las edades con derecho a votar, es decir, las tasas correspondientes a las líneas continuas de ambos sexos.

La movilidad entre estratos per cápita se reproduce en las Tabla 7a y Tabla 7 b. Se aprecia que la pauta general delineada en la Figura 2 se verifica en los tres grupos de edad y ambos sexos, en el sentido que la intensidad de la migración disminuye conforme la población envejece.

Bajo la hipótesis que la migración es un medio para mejorar las condiciones de vida, nuestra premisa es que la migración debe ser más intensa, en términos relativos, cuando se sube de estrato de bienestar, que - saliendo de una unidad geográfica - se permanece en el mismo estrato o se desciende. Y, en la emigración total, debe ser inversa, es decir, las tasas deben aumentar conforme disminuye el bienestar.

La premisa se cumple solo de manera parcial. Si se omite la etapa del ciclo de vida, en ambos sexos, igual que en los flujos, la migración es más intensa hacia el estrato de bienestar alto que hacia el más alto, excepto en 
este último donde es dentro del estrato que se tiene la tasa más alta. Asimismo, en los hombres, es más alta la tasa hacia bajo que hacia medio cuando se sale de medio y muy alto; y en las mujeres, además cuando se deja alto y se prefiere bajo a medio, y cuando se opta por permanecer en muy bajo en lugar de ascender a bajo. La hipótesis tampoco se verifica en las tasas totales de inmigración y emigración.

Tabla 7a: Tasas de emigración de la población masculina con derecho a votar por sexo, grupos de edad y condición migratoria, 2010-2015

\begin{tabular}{|c|c|c|c|c|c|c|}
\hline & (Des & zamien & por cad & 1 habita & es) & \\
\hline Estrato de & & ato de c & en (resid & ia en 20 & & \\
\hline destino & Muy alto & Alto & Medio & Bajo & Muy bajo & Inmigración \\
\hline Total & & & & & & \\
\hline Muy alto & 2.22 & 2.44 & 1.64 & 1.63 & 1.08 & 7.53 \\
\hline Alto & 2.05 & 2.60 & 2.32 & 2.78 & 2.45 & 7.83 \\
\hline Medio & 0.69 & 1.06 & 0.78 & 1.16 & 1.17 & 7.08 \\
\hline Bajo & 0.57 & 1.02 & 0.90 & 1.08 & 1.31 & 5.62 \\
\hline Muy bajo & 0.32 & 0.69 & 0.63 & 0.87 & 1.15 & 4.81 \\
\hline Emigración & 5.85 & 7.82 & 6.27 & 7.52 & 7.15 & 6.87 \\
\hline 18 a 29 años & & & & & & \\
\hline Muy alto & 3.28 & 3.96 & 3.05 & 3.00 & 2.13 & 12.90 \\
\hline Alto & 2.52 & 3.63 & 3.81 & 4.85 & 4.95 & 12.05 \\
\hline Medio & 0.80 & 1.42 & 1.09 & 1.76 & 2.04 & 10.00 \\
\hline Bajo & 0.70 & 1.27 & 1.22 & 1.56 & 2.14 & 7.57 \\
\hline Muy bajo & 0.42 & 0.87 & 0.83 & 1.23 & 1.69 & 6.29 \\
\hline Emigración & 7.72 & 11.15 & 10.00 & 12.40 & 12.95 & 10.40 \\
\hline 30 a 59 años & & & & & & \\
\hline Muy alto & 2.06 & 2.04 & 1.12 & 1.17 & 0.67 & 6.02 \\
\hline Alto & 2.14 & 2.45 & 1.88 & 2.18 & 1.51 & 6.69 \\
\hline Medio & 0.71 & 1.00 & 0.73 & 1.05 & 0.91 & 6.54 \\
\hline Bajo & 0.57 & 1.02 & 0.87 & 1.00 & 1.11 & 5.53 \\
\hline Muy bajo & 0.32 & 0.67 & 0.61 & 0.83 & 1.05 & 4.94 \\
\hline Emigración & 5.80 & 7.18 & 5.21 & 6.23 & 5.25 & 6.08 \\
\hline 60 años o má & & & & & & \\
\hline Muy alto & 0.73 & 0.72 & 0.61 & 0.46 & 0.29 & 2.36 \\
\hline Alto & 0.79 & 0.90 & 0.86 & 0.81 & 0.60 & 2.91 \\
\hline Medio & 0.37 & 0.50 & 0.32 & 0.40 & 0.34 & 3.01 \\
\hline Bajo & 0.31 & 0.48 & 0.38 & 0.42 & 0.43 & 2.23 \\
\hline Muy bajo & 0.16 & 0.35 & 0.28 & 0.33 & 0.41 & 1.83 \\
\hline Emigración & 2.36 & 2.95 & 2.45 & 2.42 & 2.07 & 2.49 \\
\hline
\end{tabular}

Fuente: tablas 2 y 4. 
Tabla 7b: Tasas de emigración de la población femenina con derecho a votar por sexo, grupos de edad y condición migratoria, 2010-2015

\begin{tabular}{|c|c|c|c|c|c|c|}
\hline \multicolumn{7}{|c|}{ (Desplazamientos por cada mil habitantes) } \\
\hline \multirow{2}{*}{$\begin{array}{l}\text { Estrato } \\
\text { de destino }\end{array}$} & \multicolumn{5}{|c|}{ Estrato de origen (residencia en 2010) } & \multirow[b]{2}{*}{ Inmigración } \\
\hline & Muy alto & Alto & Medio & Bajo & Muy bajo & \\
\hline \multicolumn{7}{|l|}{ Total } \\
\hline Muy alto & 1.89 & 2.18 & 1.54 & 1.56 & 1.01 & 6.82 \\
\hline Alto & 1.79 & 2.38 & 2.24 & 2.70 & 2.31 & 7.28 \\
\hline Medio & 0.64 & 0.99 & 0.80 & 1.21 & 1.24 & 6.99 \\
\hline Bajo & 0.53 & 1.00 & 0.94 & 1.16 & 1.50 & 5.76 \\
\hline Muy bajo & 0.33 & 0.69 & 0.69 & 1.01 & 1.56 & 5.43 \\
\hline Emigración & 5.18 & 7.23 & 6.21 & 7.64 & 7.63 & 6.61 \\
\hline \multicolumn{7}{|l|}{18 a 29 años } \\
\hline Muy alto & 3.12 & 3.89 & 2.88 & 2.96 & 1.99 & 12.88 \\
\hline Alto & 2.72 & 3.86 & 4.07 & 5.00 & 4.71 & 12.75 \\
\hline Medio & 0.94 & 1.58 & 1.36 & 2.02 & 2.43 & 11.57 \\
\hline Bajo & 0.87 & 1.60 & 1.60 & 2.05 & 2.91 & 9.61 \\
\hline Muy bajo & 0.57 & 1.16 & 1.23 & 1.90 & 3.13 & 9.37 \\
\hline Emigración & 8.21 & 12.10 & 11.15 & 13.93 & 15.17 & 11.57 \\
\hline \multicolumn{7}{|l|}{30 a 59 años } \\
\hline Muy alto & 1.64 & 1.66 & 1.10 & 1.10 & 0.60 & 5.16 \\
\hline Alto & 1.70 & 2.00 & 1.65 & 1.94 & 1.39 & 5.64 \\
\hline Medio & 0.59 & 0.84 & 0.64 & 1.01 & 0.81 & 5.67 \\
\hline Bajo & 0.46 & 0.86 & 0.77 & 0.90 & 1.01 & 4.72 \\
\hline Muy bajo & 0.27 & 0.56 & 0.53 & 0.75 & 0.99 & 4.32 \\
\hline Emigración & 4.66 & 5.93 & 4.69 & 5.70 & 4.80 & 5.20 \\
\hline \multicolumn{7}{|l|}{60 años o más } \\
\hline Muy alto & 0.73 & 0.82 & 0.55 & 0.43 & 0.40 & 2.37 \\
\hline Alto & 0.61 & 0.90 & 0.88 & 0.95 & 0.68 & 2.78 \\
\hline Medio & 0.35 & 0.41 & 0.26 & 0.37 & 0.35 & 2.80 \\
\hline Bajo & 0.23 & 0.38 & 0.30 & 0.34 & 0.41 & 1.91 \\
\hline Muy bajo & 0.12 & 0.23 & 0.22 & 0.27 & 0.34 & 1.45 \\
\hline Emigración & 2.04 & 2.73 & 2.20 & 2.36 & 2.19 & 2.32 \\
\hline
\end{tabular}

Fuente: tablas 2 y 4.

Si atendemos a las tres etapas del ciclo de vida, nuestra presunción solo se verifica en casos similares al total de flujos, en ambos sexos; incluso se aprecian apenas algunas diferencias entre los tres intervalos etarios.

En la Tabla 8 se reproducen las tasas para la movilidad intraurbana. El acrecentamiento de la mudanza conforme se es más joven se cumple en todos los desplazamientos. 
Tabla 8: Tasas de emigración de la población con derecho a votar según movilidad intraurbana, 2010-2015

\begin{tabular}{|c|c|c|c|c|}
\hline \multicolumn{5}{|c|}{$\begin{array}{l}\text { (Desplazamientos por cada mil habitantes) } \\
\text { Estrato de origen (residencia en 2010) }\end{array}$} \\
\hline $\begin{array}{l}\text { Estrato } \\
\text { de destino }\end{array}$ & Muy alto & Alto & Bajo & Entrada \\
\hline \multicolumn{5}{|l|}{ Hombres } \\
\hline Muy alto & 7.25 & 1.85 & 0.41 & 9.50 \\
\hline Alto & 3.98 & 2.70 & 1.20 & 6.89 \\
\hline Bajo & 0.59 & 2.58 & 2.28 & 7.10 \\
\hline Salida & 11.82 & 7.12 & 3.90 & 7.86 \\
\hline \multicolumn{5}{|l|}{ Mujeres } \\
\hline Muy alto & 6.67 & 1.82 & 0.44 & 8.94 \\
\hline Alto & 3.82 & 2.66 & 1.28 & 6.74 \\
\hline Bajo & 0.58 & 2.57 & 2.55 & 7.31 \\
\hline Salida & 11.07 & 7.05 & 4.27 & 7.65 \\
\hline \multicolumn{5}{|l|}{ Total } \\
\hline Muy alto & 6.95 & 1.83 & 0.43 & 9.20 \\
\hline Alto & 3.89 & 2.68 & 1.24 & 6.81 \\
\hline Bajo & 0.58 & 2.57 & 2.42 & 7.21 \\
\hline Salida & 11.42 & 7.08 & 4.09 & 7.75 \\
\hline \multicolumn{5}{|c|}{18 a 29 años } \\
\hline Muy alto & 8.85 & 2.22 & 0.61 & 11.80 \\
\hline Alto & 4.75 & 3.29 & 1.66 & 8.22 \\
\hline Bajo & 0.69 & 3.13 & 3.31 & 8.74 \\
\hline Salida & 14.29 & 8.64 & 5.59 & 9.55 \\
\hline \multicolumn{5}{|c|}{30 a 59 años } \\
\hline Muy alto & 7.36 & 1.91 & 0.39 & 9.68 \\
\hline Alto & 4.17 & 2.80 & 1.24 & 7.12 \\
\hline Bajo & 0.63 & 2.68 & 2.36 & 7.49 \\
\hline Salida & 12.15 & 7.39 & 3.99 & 8.11 \\
\hline \multicolumn{5}{|c|}{60 años o más } \\
\hline Muy alto & 2.46 & 0.76 & 0.18 & 3.31 \\
\hline Alto & 1.58 & 0.98 & 0.37 & 2.78 \\
\hline Bajo & 0.26 & 1.07 & 0.78 & 2.88 \\
\hline Salida & 4.29 & 2.80 & 1.33 & 3.01 \\
\hline
\end{tabular}

Fuente: tablas 3 y 6 .

Nuestra hipótesis general no se cumple cabalmente; sin embargo, la mayor migración dentro del estrato es común a ambo sexos y en las tres etapas del ciclo de vida. Si en todos los casos se omiten los movimientos 
dentro del estrato, mientras quienes dejan el bienestar muy alto, logran mudarse más a alto que a bajo, en los otros dos grupos, encuentran mayor acomodo al descender de categoría de bienestar.

No podemos ahora aplicar las pruebas $\chi^{2}$ para independencia, porque no tenemos un conteo, ni de Kolmogoroff y Smirnoff, pues no contamos con distribuciones. No obstante, los altos coeficientes de correlación lineal, indican que hay alta correspondencia entre las tasas de migración de las distintas orientaciones de los flujos. En la migración entre estratos de unidades geográficas:

1. Entre sexos del mismo grupo de edad 0.965 para 18-29 años, 0.991 de 30-59 años y 0.953 de 60 años o más.

2. Del mismo sexo entre grupos de edad en los hombres, 0.830 de 18-29 años respecto de 30-59 y 0.821 en relación con 60 o más, y 0.965 de $30-59$ con 60 o más.

3. Del mismo sexo entre grupos de edad en las mujeres, 0.885 de 18-29 años respecto de 30-59 y 0.889 en relación con 60 o más, y 0.954 de 30-59 con 60 o más.

En la migración entre municipios dentro de la misma zona metropolitana o conurbación, todos los coeficientes de correlación son de 0.990 o más, excepto el vínculo entre 18-29 años y 60 o más años de edad que es 0.982 .

\section{Migración Y EDUCACión}

Arriba propusimos y reconocemos debatible que, del vínculo — si bien no total ni estricto - entre bienestar y educación, se puede presumir que aquellos con menor educación formal voten por quienes les prometan mejores condiciones de bienestar a futuro, y quienes han aprobado más años en el sistema escolar, tienen una visión más amplia de la oferta política. Si esta premisa se cumpliera, al menos parcialmente, podemos suponer que en los ciudadanos que mudan su residencia se mantuviera la distribución del voto reciente de sus lugares de origen, lo cual daría una idea gruesa del impacto de la movilidad territorial en las elecciones en los lugares de destino.

En la Tabla 9 se presenta el promedio de años aprobados por los miembros de los flujos entre unidades geográficas. Un primer rasgo que salta a la vista es la mayor educación entre los hombres que en las mujeres, lo cual pone de manifiesto la ancestral discriminación hacia las mujeres al ofrecerles menores oportunidades de adiestrarse; solo en el flujo de muy bajo bienestar a alto es apenas mayor la educación media de las féminas. 
Tabla 9: Años promedio de educación e índice de Gini de la educación de la población con derecho a votar por sexo y condición migratoria entre unidades geográficas, 2010-2015

\begin{tabular}{|c|c|c|c|c|c|c|c|c|}
\hline \multicolumn{9}{|c|}{ Estrato de origen (municipio de residencia 5 años antes) } \\
\hline Estrato de destino & $\begin{array}{r}\text { Muy } \\
\text { alto }\end{array}$ & Alto & Medio & Bajo & $\begin{array}{l}\text { Muy } \\
\text { bajo }\end{array}$ & Inmigrantes & $\begin{array}{c}\text { No } \\
\text { migrantes }{ }^{\dagger}\end{array}$ & $\begin{array}{c}\text { Residencia } \\
2015\end{array}$ \\
\hline \multicolumn{9}{|l|}{ Años promedio } \\
\hline \multicolumn{9}{|l|}{ Hombres } \\
\hline Muy alto & 12.7 & 12.3 & 11.5 & 11.1 & 9.6 & 11.9 & 10.9 & 11.0 \\
\hline Alto & 12.2 & 11.3 & 11.0 & 10.6 & 9.5 & 11.1 & 10.0 & 10.1 \\
\hline Medio & 11.2 & 11.0 & 10.4 & 10.2 & 9.3 & 10.5 & 9.0 & 9.0 \\
\hline Bajo & 10.5 & 10.2 & 10.0 & 9.5 & 8.8 & 9.8 & 7.8 & 7.9 \\
\hline Muy bajo & 9.0 & 9.4 & 9.4 & 9.1 & 8.6 & 9.1 & 6.4 & 6.4 \\
\hline Emigrantes & 11.9 & 11.2 & 10.7 & 10.3 & 9.2 & & & 10.9 \\
\hline Residencia 2010 & 11.0 & 10.1 & 9.0 & 7.9 & 6.5 & 10.9 & 9.2 & 9.3 \\
\hline \multicolumn{9}{|l|}{ Mujeres } \\
\hline Muy alto & 12.3 & 11.7 & 11.3 & 10.8 & 9.5 & 11.5 & 10.5 & 10.5 \\
\hline Alto & 11.7 & 10.9 & 10.7 & 10.3 & 9.7 & 10.7 & 9.6 & 9.7 \\
\hline Medio & 10.8 & 10.6 & 10.3 & 9.9 & 9.3 & 10.2 & 8.7 & 8.7 \\
\hline Bajo & 10.3 & 10.1 & 9.8 & 9.3 & 8.8 & 9.7 & 7.6 & 7.7 \\
\hline Muy bajo & 8.9 & 9.3 & 9.4 & 9.1 & 8.6 & 9.0 & 5.9 & 6.0 \\
\hline Emigrantes & 11.5 & 10.9 & 10.5 & 10.0 & 9.2 & & & 10.5 \\
\hline Residencia 2010 & 10.5 & 9.7 & 8.7 & 7.7 & 6.1 & 10.5 & 8.9 & 8.9 \\
\hline \multicolumn{9}{|l|}{ Índice de Gini } \\
\hline \multicolumn{9}{|l|}{ Hombres } \\
\hline Muy alto & 0.18 & 0.19 & 0.20 & 0.21 & 0.23 & 0.20 & 0.23 & 0.23 \\
\hline Alto & 0.20 & 0.21 & 0.22 & 0.22 & 0.24 & 0.22 & 0.24 & 0.24 \\
\hline Medio & 0.23 & 0.23 & 0.24 & 0.24 & 0.27 & 0.24 & 0.28 & 0.28 \\
\hline Bajo & 0.25 & 0.25 & 0.26 & 0.27 & 0.29 & 0.27 & 0.33 & 0.32 \\
\hline Muy bajo & 0.27 & 0.28 & 0.30 & 0.29 & 0.32 & 0.29 & 0.38 & 0.38 \\
\hline Emigrantes & 0.21 & 0.22 & 0.23 & 0.24 & 0.27 & & & 0.23 \\
\hline Residencia 2010 & 0.23 & 0.24 & 0.28 & 0.32 & 0.38 & 0.23 & 0.29 & 0.28 \\
\hline \multicolumn{9}{|l|}{ Mujeres } \\
\hline Muy alto & 0.19 & 0.20 & 0.21 & 0.21 & 0.23 & 0.20 & 0.24 & 0.24 \\
\hline Alto & 0.20 & 0.22 & 0.23 & 0.23 & 0.24 & 0.22 & 0.26 & 0.26 \\
\hline Medio & 0.24 & 0.23 & 0.23 & 0.25 & 0.27 & 0.24 & 0.30 & 0.30 \\
\hline Bajo & 0.24 & 0.25 & 0.25 & 0.26 & 0.28 & 0.26 & 0.34 & 0.34 \\
\hline Muy bajo & 0.26 & 0.27 & 0.28 & 0.28 & 0.28 & 0.28 & 0.42 & 0.42 \\
\hline Emigrantes & 0.21 & 0.23 & 0.23 & 0.24 & 0.26 & & & 0.24 \\
\hline Residencia 2010 & 0.24 & 0.26 & 0.30 & 0.33 & 0.42 & 0.24 & 0.30 & 0.30 \\
\hline
\end{tabular}


Un postulado clásico de la migración interna es el de "selectividad", el cual se refiere a ciertas características individuales, principalmente la educación, comunes a los migrantes pero que los diferencian marcadamente de aquellos que han decidido permanecer en el lugar de origen. En su trabajo pionero sobre Estados Unidos, Blau y Duncan (1967) confirmaron empíricamente el postulado teórico de la selectividad positiva de los migrantes, es decir, que tienen mayores niveles de educación y mayor movilidad social que los no migrantes. ${ }^{10}$

Esta premisa se cumple, cabalmente, en los dos paneles superiores de la Tabla 9. Si se comparan cada una de las primeras cinco columnas con los no migrantes del mismo estrato, se puede ver que en casi todos los casos los años aprobados, en promedio, son mayores en los migrantes que entre aquellos que permanecen en la unidad geográfica, e incluso en la emigración total. Las excepciones en ambos sexos se advierten entre quienes dejan muy alto para asentarse en bajo (10.5 años en hombres y 10.3 años en mujeres) y muy bajo (9.0 y 8.9 años, respectivamente), que poseen menor adiestramiento que los no migrantes (10.9 y 10.5 años, respectivamente); y aquellos que se mudan de alto a muy bajo ( 9.4 años en hombres y 9.3 años en mujeres), cuya educación formal es inferior a quienes permanecen en alto (10.0 y 9.6 años, respectivamente).

Otro hecho que sobresale en los dos primeros paneles de la Tabla 9 es que la educación promedio aumenta conforme sube el nivel de bienestar de la unidad geográfica de origen (síganse las columnas para cada renglón) o de destino (véanse los renglones para cada columna). Apenas se perciben seis excepciones: bajo la óptica del origen, es mayor la formación de las mujeres que se establecen en alto bienestar que en muy alto cuando salen de muy bajo; y, desde la perspectiva del destino, quienes arriban a muy bajo, en ambos sexos es mayor la educación de aquellos que proceden de alto que de muy alto, y en las mujeres también quienes dejan medio bienestar respecto de aquellas que emigran de alto y de muy alto, y las que salen de bajo con más años aprobados que las que se mudan de muy alto.

Los índices de Gini para los flujos migratorios entre estratos se muestran en los paneles inferiores de la Tabla 9. Este indicador resumen la desigualdad en la oferta educativa: si vale cero, se tiene la perfecta distribución de la educación; cuando es igual a uno señala que la concentración es total.

\footnotetext{
${ }^{10}$ Chiswick (2000) cita varios estudios sobre migración interna en Estados Unidos y Canadá que corroboran el hallazgo, e incluso que, aunque la selectividad disminuye conforma aumenta el número de traslados, los migrantes siguen siendo positivamente más selectos que aquellos que nunca se movieron.
} 
En general, conforme aumenta el nivel de bienestar de la unidad geográfica, sube la equidad en la educación (disminuye el índice de Gini), tanto en los flujos específicos como en los totales, bajo la óptica de origen o de destino, y entre los no migrantes. Las excepciones se tienen solo bajo la óptica del destino; el eventual lector las puede constatar en los arribos a los estratos de medio y muy bajo bienestar.

Dejamos de lado la inspección para la movilidad intra urbana, pues al mantenerse en la misma zona metropolitana o conurbación, más que selectividad de quienes se desplazan, se vería el nivel de bienestar vinculado al nivel educativo, ya que este es una de las variables consideradas por el CONEVAL en el cálculo de la pobreza multidimensional.

\section{MigRación y SALARIOS}

Varias décadas antes que Blau y Duncan propusieran la selectividad, Ravenstein $(1885,1889)$ postuló que el deseo de vivir mejor era la razón principal para migrar, hipótesis que actualmente se considera evidenciada y se traduce en allegarse más recursos monetarios, sea para escapar de la pobreza, sea para recuperar el estatus perdido.

En la Tabla 10 se presentan los ingresos laborales para nuestro esquema migratorio. Tomamos salarios mínimos, en lugar de pesos corrientes, bajo la premisa que la diferencia regional en los salarios mínimos equipara el poder de compra de bienes y servicios en todos los municipios.

Se advierte un pago mayor a los hombres que a las mujeres, excepto en los traslados dentro del estrato de más bajo bienestar y entre los no migrantes del mismo conjunto de unidades geográficas. Debido a que, inexplicablemente, en la Encuesta Intercensal de 2015 no se preguntó por las horas trabajadas en la semana anterior, no se pueden estandarizar los salarios por hora y así tener una inspección más precisa del distanciamiento en las remuneraciones entre los sexos.

Dada la manera como construimos los estratos, se espera que el pago al trabajo aumente conforme sube el nivel de bienestar. Igual que en el caso de la educación, la propuesta se satisface bajo la óptica de la emigración en los cinco estratos en ambos sexos, excepto en las salidas femeninas de muy bajo bienestar, donde la retribución media es mayor entre quienes se mudan dentro del estrato que en aquellas que se dirigen a bajo bienestar. 
Tabla 10: Salarios mínimos promedio e índice de Gini de las percepciones de la población con derecho a votar por sexo y condición migratoria entre unidades geográficas, 2010-2015

Estrato de origen (municipio de residencia 5 años antes)

\begin{tabular}{|c|c|c|c|c|c|c|c|c|}
\hline Estrato de destino & $\begin{array}{r}\text { Muy } \\
\text { alto }\end{array}$ & Alto & Medio & Bajo & $\begin{array}{l}\text { Muy } \\
\text { bajo }\end{array}$ & Inmigrantes & $\begin{array}{c}\text { No } \\
\text { migrantes }^{\dagger}\end{array}$ & $\begin{array}{c}\text { Residencia } \\
2015\end{array}$ \\
\hline \multicolumn{9}{|l|}{ Salarios mínimos } \\
\hline \multicolumn{9}{|l|}{ Hombres } \\
\hline Muy alto & 6.4 & 5.4 & 4.2 & 3.8 & 3.1 & 5.2 & 4.4 & 4.4 \\
\hline Alto & 5.6 & 4.6 & 3.8 & 3.5 & 2.8 & 4.3 & 3.6 & 3.6 \\
\hline Medio & 4.4 & 4.5 & 3.4 & 3.1 & 2.7 & 3.8 & 2.9 & 3.0 \\
\hline Bajo & 3.6 & 3.4 & 3.3 & 3.0 & 2.5 & 3.2 & 2.4 & 2.4 \\
\hline Muy bajo & 2.3 & 2.5 & 2.5 & 2.4 & 2.2 & 2.4 & 1.6 & 1.6 \\
\hline Emigrantes & 5.4 & 4.5 & 3.7 & 3.3 & 2.7 & & & 4.1 \\
\hline Residencia 2010 & 4.5 & 3.6 & 3.0 & 2.4 & 1.6 & 4.1 & 3.3 & 3.3 \\
\hline \multicolumn{9}{|l|}{ Mujeres } \\
\hline Muy alto & 4.8 & 3.8 & 3.0 & 3.0 & 2.4 & 3.7 & 3.5 & 3.5 \\
\hline Alto & 3.9 & 3.4 & 2.8 & 2.7 & 2.3 & 3.1 & 2.9 & 2.9 \\
\hline Medio & 3.2 & 3.2 & 2.7 & 2.6 & 2.3 & 2.8 & 2.4 & 2.4 \\
\hline Bajo & 2.8 & 2.6 & 2.5 & 2.4 & 2.0 & 2.5 & 2.0 & 2.0 \\
\hline Muy bajo & 2.1 & 2.2 & 2.4 & 2.3 & 2.2 & 2.2 & 1.6 & 1.6 \\
\hline Emigrantes & 4.0 & 3.3 & 2.8 & 2.7 & 2.3 & & & 3.1 \\
\hline Residencia 2010 & 3.5 & 2.9 & 2.4 & 2.1 & 1.6 & 3.1 & 2.8 & 2.8 \\
\hline \multicolumn{9}{|l|}{ Índice de Gini } \\
\hline \multicolumn{9}{|l|}{ Hombres } \\
\hline Muy alto & 0.46 & 0.47 & 0.46 & 0.44 & 0.38 & 0.47 & 0.45 & 0.46 \\
\hline Alto & 0.46 & 0.44 & 0.41 & 0.40 & 0.37 & 0.45 & 0.43 & 0.44 \\
\hline Medio & 0.48 & 0.46 & 0.42 & 0.40 & 0.40 & 0.45 & 0.43 & 0.43 \\
\hline Bajo & 0.48 & 0.48 & 0.46 & 0.45 & 0.42 & 0.47 & 0.46 & 0.46 \\
\hline Muy bajo & 0.54 & 0.51 & 0.49 & 0.48 & 0.49 & 0.50 & 0.58 & 0.58 \\
\hline Emigrantes & 0.48 & 0.47 & 0.44 & 0.43 & 0.41 & & & 0.47 \\
\hline Residencia 2010 & 0.46 & 0.44 & 0.43 & 0.46 & 0.57 & 0.47 & 0.48 & 0.48 \\
\hline \multicolumn{9}{|l|}{ Mujeres } \\
\hline Muy alto & 0.48 & 0.47 & 0.43 & 0.46 & 0.38 & 0.48 & 0.48 & 0.48 \\
\hline Alto & 0.48 & 0.48 & 0.45 & 0.45 & 0.40 & 0.47 & 0.47 & 0.47 \\
\hline Medio & 0.51 & 0.50 & 0.48 & 0.47 & 0.45 & 0.49 & 0.49 & 0.49 \\
\hline Bajo & 0.52 & 0.51 & 0.48 & 0.49 & 0.47 & 0.50 & 0.51 & 0.51 \\
\hline Muy bajo & 0.55 & 0.54 & 0.49 & 0.52 & 0.53 & 0.53 & 0.60 & 0.60 \\
\hline Emigrantes & 0.50 & 0.49 & 0.46 & 0.47 & 0.44 & & & 0.49 \\
\hline Residencia 2010 & 0.48 & 0.47 & 0.49 & 0.51 & 0.59 & 0.49 & 0.50 & 0.50 \\
\hline
\end{tabular}


Bajo el enfoque de la inmigración, se advierten las mismas excepciones para ambos sexos: en las llegadas hacia medio bienestar, donde es mayor el salario para quienes proceden de alto bienestar que para los que dejaron muy alto, y las entradas en unidades territoriales de muy bajo bienestar, donde las percepciones monetarias son mayores en los procedentes de alto, medio y bajo bienestar que los que se marchan de muy alto; y ahí mismo, en las mujeres también aquellas que parten de muy bajo bienestar.

Los índices de Gini para la concentración de los ingresos por trabajo en los flujos migratorios entre estratos se muestran en los paneles inferiores de la Tabla 10. Se aprecia cierto patrón claro bajo la óptica de la emigración masculina: para los cinco orígenes y no migrantes, una desigualdad mayor entre quienes se dirigen al estrato muy alto que los que llegan al alto, solo para luego aumentar en las corrientes que van hacia los estratos de menor bienestar, excepto en los que salen de baja, donde el descenso del índice de Gini avanza hasta el bienestar medio. En las mujeres, en cambio, el acrecentamiento en la desigualdad de las retribuciones aumenta conforme disminuye el nivel de bienestar, excepto en las que dejan medio bienestar para irse a bajo, y las que salen de bajo, con menor inequidad al arribar a alto que a muy alto bienestar.

De acuerdo con la perspectiva de la inmigración, en los varones se advierte un patrón más nítido que en las féminas: la concentración de las remuneraciones disminuye conforme desciende el nivel de bienestar de origen, siendo las excepciones las mudanzas dentro de las categorías extremas de bienestar, y las llegadas hacia medio procedentes de muy bajo. En las mujeres, la pauta masculina se rompe al contrastar los orígenes de bienestar medio y bajo, excepto en las llegadas a bienestar medio donde el patrón femenil se cumple de manera cabal.

La liga entre inequidad y migración se puede ver también mediante el concepto de privación relativa propuesto por Stark (1983), en el sentido que, al compararse con sus pares, el individuo o el hogar percibe la situación de desigualdad social y, a través de la migración, busca equilibrar su posición económica y social. Bajo este principio, Stark y Wang (2000) sugieren que a mayor grado de inequidad, mayor movilidad territorial. Para ver si se cumple esa hipótesis en nuestro caso, contrastamos las tasas (Tabla 7a y Tabla 7b) con los cocientes del índice de Gini (Tabla 10). Sea $M_{\mathrm{ij}}$ la tasa de migración del estrato $i$ hacia el estrato $j$ y $G_{i}$ y $G_{j}$ los índices de Gini en los estratos de origen (renglón residencia 2010 en la Tabla 10) y destino (columna residencia 2015 en la Tabla 10), respectivamente. 
Cabe, sin embargo, hacer una precisión. El individuo o su familia pueden identificar el grado de desigualdad reinante en el estrato $i$ donde viven, pero es difícil argumentar que tengan una idea precisa de la situación en los posibles destinos $j$; no obstante, si pensamos que pueden tener alguna información de las condiciones en otras realidades, mediante redes sociales, medios impresos o electrónicos, etc., se puede aceptar que el cociente de alguna manera refleja la decisión racional individual, familiar o comunitaria para seleccionar el estrato $j$ sobre cualquier otro. Así, relacionamos $M_{\mathrm{ij}} \operatorname{con} \mathrm{G}_{\mathrm{j}} / \mathrm{G}_{\mathrm{i}}$.

El vínculo es muy débil: los coeficientes de correlación lineal son 0.398 para hombres y 0.554 para mujeres.

\section{Conclusiones}

En este trabajo inspeccionamos la migración interna de los ciudadanos mexicanos, es decir, aquellos que pueden votar. En vez de regiones territoriales contiguas e independientes, elegimos el criterio de estratos de bienestar, bajo la premisa que dado el vínculo entre bienestar y educación, es factible que los menos educados voten por quienes les prometan las mejores condiciones de bienestar a futuro, mientras aquellos con más años aprobados visualizan más la oferta global de los contendientes políticos.

Nuestras fuentes de datos son la Encuesta Intercensal 2015, de donde extrajimos los migrantes, su educación y salarios, y las estimaciones municipales de pobreza del CONEVAL.

Bajo el criterio que la migración implica quedar fuera del área de influencia de una ciudad, y dado que en la Encuesta Intercensal 2015 se capta la residencia anterior por municipio, consideramos como unidades geográficas a todos los municipios del país, excepto aquellos que formaban parte de una zona metropolitana o conurbación, circunscritas a dos o más municipios, donde tomamos como una sola unidad geográfica a cada una de esas zonas metropolitanas o conurbaciones. A las mudanzas entre unidades geográficas las llamamos migraciones; a los desplazamientos entre municipios dentro de una misma zona metropolitana o conurbación específica los denominamos movimientos intra urbanos.

En cuanto a la migración, el patrón general, tanto en los totales como en los tres grupos de edad considerados, se advirtió que los mayores traslados se dirigieron al estrato de alto bienestar, igual sucedió como las tasas de emigración entre y dentro de los estratos, excepto en el grupo de más alto bienestar, cuyo monto y tasa más alta se observó en la migración al interior del estrato. 
La movilidad intra urbana mostró que el volumen más alto de desplazamientos se da dentro del mismo estrato, pauta que se replicó en las tasas de migración.

La contribución de la movilidad al crecimiento de la ciudadanía, esto es, la migración neta o saldo neto migratorio, exhibió — sin embargo- un escenario distinto. En la migración, los saldos más cuantiosos correspondieron al estrato de muy alto bienestar, seguido de la categoría intermedia, con voluminosas pérdidas en los dos estratos de menor bienestar. Sin embargo, el comportamiento difirió según la etapa del ciclo de vida, en ambos sexos.

Del lado de la movilidad intra urbana, el escenario se invirtió en los tres grupos de edad: la mayor pérdida de población, por el cambio de la residencia, se observó en el estrato de muy alto bienestar, de mucha menor cuantía pero aún con decremento en el de alto, con la consecuente ganancia en el conjunto de bienestar bajo. Presumimos que este comportamiento, propio del medio urbano, se pudo deber al difícil acceso al suelo habitacional de mayor precio (vinculado a los municipios de más alto bienestar) en zonas metropolitanas y conurbaciones.

En la educación de los ciudadanos migrantes, constatamos el viejo postulado de la selectividad, en el sentido que, efectivamente, poseen más años aprobados en el sistema escolar formal quienes se desplazan que aquellos que no lo hacen; y bajo el criterio del índice de Gini, que la concentración del capital humano aumenta conforme disminuye el nivel de bienestar.

La ancestral premisa, que la causa principal de la migración es la búsqueda de mayores ingresos monetarios, se satisfizo, pues los salarios medios de los emigrantes excedieron a las retribuciones de los no migrantes.

Espero que los resultados de esta inspección despierten el interés por analizar la movilidad territorial de la población con derecho a votar; quizás algún eventual lector examine el posible impacto de la migración en el voto de una unidad geográfica específica.

\section{REFERENCIAS BIBLIOGRÁFICAS}

Blau, Peter y Duncan, Otis, 1967, The American occupational structure. John Wiley, New York.

Chiswick, Barry, 2000, “Are immigrants favorably self-selected?", en Brettel, Caroline y Hollifield, James, Migration theory. Talking across disciplines. Routledge, New York: 61-76. 
CONEVAL, 2014, Metodología para la medición multidimensional de la pobreza en México. México: Consejo Nacional de Evaluación de la Política de Desarrollo Social.

CONEVAL, 2017, Anexo estadístico de pobreza a nivel municipio 2010 y 2015, recuperado de https://www.coneval.org.mx/Medicion/Paginas/AE_pobreza_municipal.aspx

Elizaga, Juan C. y Macisco Jr. John, 1975, Migraciones internas. Teoría, método y factores sociológicos. Santiago de Chile: Centro Latinoamericano de Demografía.

Kolmogoroff, Andrey, 1941, "Confidence limits for an unknown distribution function”, in The Annals of Mathematical Statistics, vol. 12, núm. 4, 461-463

Martínez, Julio, 2017, "Una aproximación metodológica al uso de datos de encuestas en hogares". Realidad, Datos y Espacio, vol. 8, núm. 2, 53-71.

Oberai, Amarjit, 1989, Migración, urbanización y desarrollo. Ginebra: Oficina Internacional de Trabajo. Estudios básicos para la formación en población, recursos humanos y planificación del desarrollo 5 .

Oestle, Bernard, 1973, Estadística aplicada. México: Editorial Limusa-Wiley.

Partida, Virgilio, 2006, Migración interna en México. Una perspectiva multirregional. Tesis doctoral. México: Universidad Nacional Autónoma de México.

Ravenstein, Ernest, 1885, "The laws of migration", in Journal of the Statistical Society of London, vol. 48, núm. 2, 167-235

Ravenstein, Ernest, 1889, "The laws of migration", in Journal of the Royal Statistical Society, vol. 52, núm. 2, 241-305

SAGARPA, CONAPO e INEGI, 2018, Delimitación de las Zonas Metropolitanas de México 2015. México: Secretaría de Desarrollo Agrario, Territorial y Urbano, Consejo Nacional de Población e Instituto Nacional de Estadística y Geografía

SEDESOL y CONAPO, 2012, Sistema Urbano Nacional 2012. Catálogo. México: Secretaría de Desarrollo Social y Consejo Nacional de Población.

Stark, Oded y Wang, You, 2000, A theory of migration as a response to relative deprivation, Bonn: Center for Development Research, Universität Bonn, Discussion Papers on Development Policy 25.

Stark, Oded, 1983, Rural-to-urban migration in LDCs: A relative deprivation approach, Cambridge, Massachussetts: Migration and Development Program, Harvard University. Discussion Paper 1.

STATA, 2003, STATA release 8. Cluster analysis. College Station, Texas: Stata Press. 


\section{RESUMEN CURRICULAR DEL AUTOR}

\section{Virgilio Partida Bush}

Actuario y Doctor en Ciencias Políticas y Sociales con orientación en Sociología por la Universidad Nacional Autónoma de México y Maestro en Demografía por El Colegio de México. Profesor en la Facultad de Ciencias de la Universidad Nacional Autónoma de México, El Colegio de México, El Colegio de la Frontera Norte, Centro Interamericano de Estudios de Seguridad Social (CIESS), Instituto Tecnológico Autónomo de México y en la Facultad Latinoamericana de Ciencias Sociales, donde actualmente se desempeña como profesor e investigador. Es autor o coautor de 22 libros y más de cien artículos, capítulos en libros y colaboraciones periodísticas. Es miembro del Sistema Nacional de Investigadores nivel III y Profesor Honorífico del CIESS.

Dirección electrónica: vpartida@prodigy.net.mx 